Caso para Ensino

\title{
Pandemia se Combate em Rede! Desafios da COVID-19 no Nordeste do Brasil
}

\author{
Pandemic Fights in a Network! COVID-19 Challenges in Northeast Brazil
}

Disciplina: Gestão Pública

Raphael Jesus Campos de Andrade ${ }^{10}$ José Milton de Sousa-Filho ${ }^{2 \oplus}$

Fátima Evaneide Barbosa de Almeida ${ }^{3}$ Samuel Façanha Câmara ${ }^{40}$

\section{INTRODUÇÃO}

Nordeste, 11 de março de 2020.

"A Organização Mundial da Saúde (OMS) declarou nesta quarta-feira que o surto de COVID-19 já pode ser considerado como uma pandemia. O novo coronavírus, como ficou conhecido, já infectou mais de 110.000 pessoas em todo o mundo desde o final de dezembro. De acordo com Tedros Adhanom Ghebreyesus, diretor da OMS, o surto está sendo avaliado a todo momento e é grande a preocupaçáo com os níveis alarmantes de propagação do vírus e de inação dos países e instituiçóes. A doença surgiu na cidade de Wuhan, na China, no final do ano passado, mas se espalhou pelo mundo; Itália, Irã e Coreia do Sul são especialmente afetados, mas todos os continentes, com exceção da Antártida, já registraram casos de infectados" dizia o repórter da rádio.

Mesmo com a doença bastante disseminada por toda a Europa e várias outras partes do mundo e já tendo chegado ao Brasil há cerca de duas semanas, Miguel Bastos, gerente de inovação do Sistema Indústria, realmente não desconfiava que em muito pouco tempo suas tarefas cotidianas deixariam de ser prioridade e que seus desafios institucionais estariam completamente relacionados ao combate à COVID-19.

\begin{tabular}{|c|c|c|c|c|c|c|c|c|c|}
\hline & 1 & 2 & 3 & 4 & 5 & 6 & 7 & 8 & 9 \\
\hline $1^{a}$ rodada & $\frac{9}{2}$ & $\stackrel{8}{2}$ & & & & & & & \\
\hline $2^{\mathrm{a}}$ rodada & $\stackrel{9}{1}$ & & & & & & & & \\
\hline
\end{tabular}

Classificaçāo JEL: A20, 13, N16. Editor-chefe: Wesley Mendes-Da-Silva (Fundação Getulio Vargas, EAESP, Brasill) Editora Associada: Paula C. P. de S. Chimenti (Universidade Federal do Rio de Janeiro, COPPEAD, Brasil) Editor Convidado: Leonardo Marques (Universidade Federal do Rio de Janeiro, COPPEAD, Brasil) (1) Pareceristas: Kenyth Alves de Freitas (Fundação Getulio Vargas, EAESP, Brasil) (c) Um dos indivíduos revisores optou por não ter sua identidade divulgada.

Relatório de Revisão por Pares: O Relatório de Revisão por Pares está disponivel neste link externo. 
O Sistema Indústria representa o setor industrial da região Nordeste, atuando desde 1950, e possui 40 sindicatos patronais associados. É composto pelas seguintes entidades: o Serviço de Formação Industrial do Nordeste (Sefin), o Serviço de Saúde da Indústria do Nordeste (Sesano), e o Instituto de Desenvolvimento Empresarial e de Carreiras (Ideca). A atuação do Sistema Indústria consiste em seis eixos estratégicos: educação básica indutora da melhoria da qualidade educacional do Nordeste, educação profissional e superior voltadas para o futuro do trabalho na indústria, modernização industrial intensiva em inovação, soluçóes em gestão da inovação para o setor produtivo por meio de processos ágeis, segurança e saúde na Indústria integradas no trabalho para redução de riscos e custos, internacionalização da Indústria e promoçâo de investimentos.

Com apenas cinco minutos de atraso, Miguel entrou na sala de reunióes. Lá estavam: Renato Amarante, presidente do Sistema Indústria e sua equipe - Simplício Neto, diretor de inovação; Pedro Henrique França, diretor de tecnologia; Tayrone Sales, gerente de tecnologia; e José Armani, supervisor de produção.

- ... gostaria, entấo, da contribuição de todos vocês acerca do que devemos fazer... - disse Renato.

- Presidente, não temos outra opçáo que não seja fechar tudo...

- Fechar tudo, Simplício?! Ficou maluco?!

- Infelizmente, Pedro, o Simplício teve a coragem de encarar logo os fatos de frente... Pelo que temos acompanhado junto ao governo regional, a situação é mesmo muito séria...

- Chegamos mesmo a esse ponto, presidente? Qual a posição do governo?

- Chegamos, Pedro... As projeçóes do Comitê Regional de Crise não são nada animadoras... A tendência é fechar praticamente todas as atividades econômicas, com exceção dos serviços essenciais... Deverá ser publicado um decreto nesse sentido, estabelecendo os termos...

- Sugiro montarmos um plano de contingência, presidente Renato, com medidas que nos permitam continuar trabalhando de maneira remota... Precisamos estreitar o relacionamento com nossos clientes, fortalecer o apoio às indústrias...

- Ótima sugestão, Miguel! Compensando seu atraso habitual... Muito bem!

- Muito obrigado, presidente! - disse Miguel já de cabeça baixa, evitando o olhar dos colegas.

- Então, vamos ao trabalho, pessoal! Vocês têm uma semana para dar todas as condições para que nossos colaboradores sigam com suas atividades de casa. Vamos acompanhar a experiência para ver o que acontece... - anunciou Renato com receio de sua decisão e preocupado com o que ainda estava por vir.

\section{AÇÕES EMERGENCIAIS}

A pandemia havia sorrateiramente se instalado no nordeste brasileiro. Da noite para o dia, a táo temível realidade de milhares de infectados e de centenas de mortes diárias colapsando o sistema de saúde e o sistema funerário da Itália e da Espanha agora parecia estar sendo transportada da TV (ou talvez da tela de um 'filme-catástrofe') para o cotidiano dos nordestinos. Nesse contexto inicial de espanto e incertezas, dezenas de instituiçóes públicas e privadas passaram a realizar, de maneira improvisada e não coordenada, diversas açóes emergenciais de mitigação e combate à disseminação da COVID-19 em todo o Nordeste.

Primeiramente, um grupo de profissionais de gestão de projetos, processos e inovação, liderado por Sandoval Ampere, um renomado gestor de projetos local, criou um movimento da sociedade civil para salvar vidas, formando três grupos de trabalho compostos por voluntários. $\mathrm{O}$ primeiro grupo ficou responsável por dimensionar as necessidades do sistema de saúde por produtos escassos no mercado e necessários para o provimento de serviços médicos, como também por realizar análises de requisitos (materiais, quantidades, métodos de produçáo, etc.) para a prototipagem e produçáo desses produtos. $\mathrm{O}$ segundo grupo se comprometeu com a escrita de projetos para captação de recursos junto aos editais de subvenção econômica para combate à COVID-19 lançados por agências de fomento de todo o Brasil. O terceiro grupo se configurou como uma área de comunicação e marketing do movimento, que passou a se chamar Movimento Respira Nordeste, estruturando sua identidade visual, seus perfis nas redes sociais e seus materiais de comunicação em geral.

Rapidamente, integraram-se ao movimento dezenas de profissionais das mais diversas áreas de conhecimento, empresários de diferentes setores e voluntários de todos os tipos, interessados em contribuir com recursos, competências, doaçôes em dinheiro, etc. $\mathrm{O}$ trabalho incansável de Sandoval, líder do movimento, foi crucial para a mobilização de tantos voluntários altamente qualificados e dedicados.

Dentre os diversos voluntários sensibilizados por Sandoval, foram se destacando nos grupos de trabalho, com contribuiçóes assertivas sobre como desenvolver determinadas soluçóes, vários especialistas da área de tecnologia do Sistema Indústria. Devido à forte participação do corpo técnico, pouco a pouco o time de gestores e as 
Diretorias de Tecnologia e de Inovação do Sistema Indústria, comandadas, respectivamente, por Pedro Henrique França e por Simplício Neto, agregaram-se informalmente ao Movimento Respira Nordeste, o que resultaria em açóes conjuntas, ainda que pontuais, de desenvolvimento de soluções, fabricação de produtos e manutenção de equipamentos voltados para o alívio da crise.

Em paralelo e desconectado dessas iniciativas, Renato, presidente do Sistema Indústria, mobilizou o setor empresarial para que destinasse recursos para a melhoria das condiçōes de trabalho e de infraestrutura do sistema regional de saúde, arrecadando em um curto espaço de tempo mais de $\mathrm{R}$ \$ 10 milhóes que seriam diretamente aplicados nas açóes de combate à COVID-19 do próprio Sistema Indústria.

Dezenas de outras instituiçóes seguiram isoladamente o seu próprio curso de resposta emergencial à crise sanitária, que envolveu açôes como: composição de propostas e protocolos para a retomada econômica, campanhas solidárias, empréstimos de impressoras 3D para fabricaçáo de EPIs, assessorias e consultorias remotas gratuitas para empresas acerca de formas de acesso a linhas de crédito e outros temas de interesse, desenvolvimento de algoritmos de inteligência artificial para diagnóstico e monitoramento da doença, dentre muitas outras iniciativas com diferentes níveis de maturidade e impacto.

Não obstante, todos esses esforços institucionais inicialmente passaram a enfrentar pelo menos dois grandes desafios comuns. Primeiramente, a falta de integração entre as iniciativas, dado o envolvimento de uma quantidade muito grande de pessoas, um fluxo de informações muito intenso e difícil de coordenar e a falta de curva de experiência em temas tão complexos e repletos de incertezas. Além disso, todas as iniciativas passaram a conviver com dúvidas acerca do que de fato precisava ser adquirido e/ou produzido, visto que as demandas advinham principalmente do poder público - do Comitê Regional de Crise do governo, dos órgãos de saúde regionais e de seus equipamentos (UPAs, hospitais, etc.).

Nesse momento, ganha destaque a figura de Miguel, nosso protagonista, que estava ligado ao Sistema Indústria, atuava na área de inovação em rede e, principalmente, tinha uma experiência recente acerca de desastres industriais. Essas características qualificaram Miguel, que passaria a ser peça central nesse contexto de iniciativas descoordenadas...

\section{COORDENAÇÃO E LIDERANÇA}

Há muitos anos, Miguel estava bastante integrado às iniciativas de inovação das instituições nordestinas, tendo, inclusive, participado ativamente da construçấo de boa parte delas. Com o advento da pandemia, acompanhava à média distância as respostas de dezenas de instituições, estando todas internamente atordoadas e externamente descoordenadas. Como gerente de inovação do Sistema Indústria, ficou responsável por prover soluçóes inovadoras de combate à COVID-19 para o sistema de saúde e para o setor produtivo. Além disso, tinha assento no Conselho Superior da Fundação de Amparo à Pesquisa do Nordeste (Fapne), e por conta disso, recebeu uma ligaçáo de Jairo Sousa, diretor da Fapne.

- Alô, Miguel? Aqui é o Jairo... Pode falar?

- Oi, Jairo. Tudo bem? Posso sim...

- Estamos precisando da sua ajuda... Recebemos várias demandas do sistema regional de saúde e precisamos apresentar uma resposta estruturada... As coisas estáo bem complicadas no governo... Segundo Xerxes Filho, que atua no governo regional e é responsável pelos indicadores epidemiológicos, o sistema de saúde está caminhando a passos largos para o colapso!

- Você disse demandas do sistema de saúde?! respondeu Miguel entusiasmado!

- Exatamente! Todo dia o secretário de saúde liga... O chefe da Casa Civil, o secretário de ciência e tecnologia... Até o governador, que anda bastante preocupado com as compras de equipamentos médico-hospitalares e de proteção individual que podem demorar muito a chegar da China! O Márcio Albuquerque, superintendente do Instituto Regional de Saúde... Você conhece... Também nos procurou em busca de apoio... Parece que o Instituto acabou de concluir um inventário acerca dos ventiladores mecânicos do Nordeste, e descobriram que boa parte está completamente obsoleta ou precisando de manutenção...

- Jairo, você só pode estar brincando... Desde que começou esse isolamento social que eu assisto a dezenas de instituiçóes se mobilizando de todas as formas para resolver problemas do sistema de saúde que não se apresentam de forma clara e estruturada... Ninguém tem respostas objetivas para perguntas básicas: Quais equipamentos estão em falta? Quantos? Para quais hospitais? E você vem me dizer que o Comitê Regional de Crise e demais interessados todo dia batem na sua porta clamando por soluçóes? Que maravilha!!! Podemos começar a direcionar os esforços, entáo!

- Excelente, Miguel! Sabia que acharia um caminho conversando com você... O que acha de elaborarmos um projeto de inovação para a Fapne alinhando essas iniciativas que você conhece?

Foi entâo que as ações finalmente começaram a se integrar... Miguel aproximou lideranças da Fapne e do Sistema Indústria em torno do tema de combate à pandemia. Com efeito, a Fapne começou a conhecer e a apoiar os esforços do Sistema Indústria, fazendo conexões com os 
órgãos do sistema de saúde e facilitando o levantamento de requisitos dos produtos a serem desenvolvidos.

Miguel passou a liderar o time do escritório de projetos do Sistema Indústria, na perspectiva de redigir para a Fapne um projeto voltado para a manutenção de ventiladores mecânicos pulmonares obsoletos do governo regional, para o desenvolvimento emergencial de novos ventiladores funcionais de baixo custo e para a fabricaçáo em larga escala de diferentes equipamentos de proteção individual. $\mathrm{O}$ projeto ficou pronto em apenas dois dias e envolveu não apenas o Sistema Indústria, mas diversas instituiçôes participantes na promoção de medidas de alívio, como a Universidade Federal do Nordeste (UFN), a Associação de Prototipagem Regional (APR) e o próprio Movimento Respira Nordeste, mesmo não estando ainda constituído juridicamente. Em menos de uma semana, o projeto foi avaliado e aprovado pela Fapne, propiciando, nos 30 dias subsequentes, os seguintes resultados parciais:

1. O Sistema Indústria passou a produzir os primeiros protótipos dos ventiladores pulmonares de baixo custo e diversos equipamentos de proteção individual em larga escala;

2. O corpo administrativo do Sistema Indústria se mobilizou para fornecer o devido suporte ao projeto, realizando compras de insumos e matérias-primas e organizando a logística;

3. A Secretaria de Saúde do governo regional passou a atuar na validação dos protótipos de ventiladores mecânicos desenvolvidos;

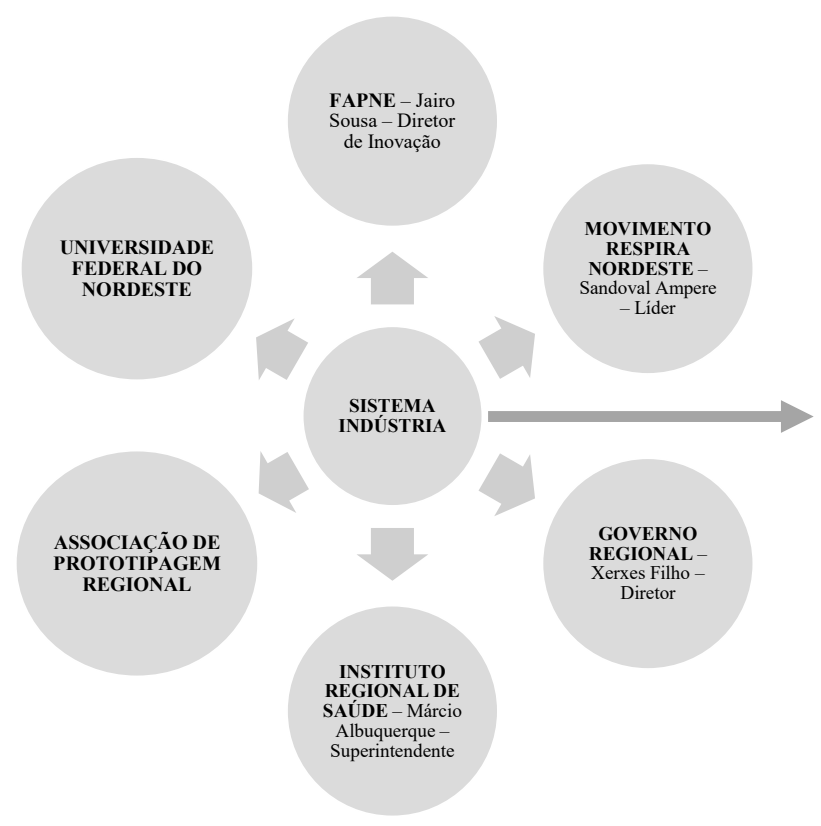

Figura 1. Rede de coordenação e liderança. Fonte: Elaborado pelos autores.
4. A unidade de manutenção industrial do Sistema Indústria foi instituída pelo governador como centro oficial de manutenção de ventiladores mecânicos do governo regional;

5. Empresas privadas se associaram ao Sistema Indústria como fabricantes e doadoras de equipamentos de proteção individual, maximizando a capacidade produtiva instalada;

6. O Movimento Respira Nordeste ganhou destaque na grande mídia nacional;

7. A alta gestão do Sistema Indústria autorizou o uso de sua marca como apoiadora do Movimento Respira Nordeste;

8. Outros setores do Sistema Indústria, como a Gerência de Operaçóes, a Gerência de Planejamento e a Gerência de Tecnologia, a pedido da presidência, passaram a ter ciência das iniciativas, a se engajar no projeto e a demandar alinhamento interno para contribuição efetiva;

9. O Movimento Respira Nordeste obteve doação de grande quantidade de acetato de um empresário e encaminhou o material para o Sistema Indústria utilizar como matéria-prima em seu processo de fabricação de equipamentos de proteção individual.

A Figura 1 apresenta a rede de coordenação e liderança formada para o combate à COVID-19.

\section{SISTEMA INDÚSTRIA}

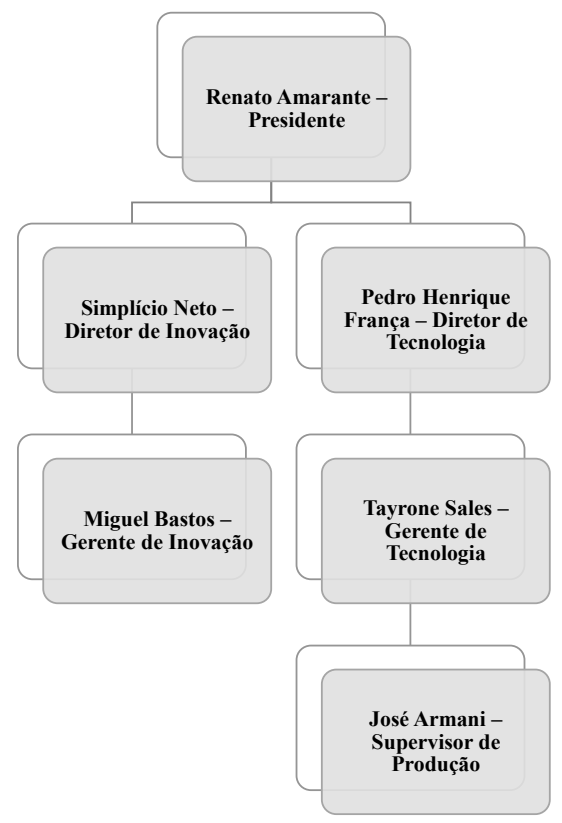




\section{INEFICIÊNCIAS NO PROCESSO DE COOPERAÇÃO EM REDE}

- E então, Miguel? Resolveu largar a vida boa da videoconferência e observar quem trabalha?

- Pois é, Armani... Precisando esticar as pernas... E você? O que faz de bom por aqui?

- O de sempre... Supervisionando a produção e entregando resultado...

- Brincadeiras à parte, o processo produtivo que vocês montaram realmente é de excelência! Padrão "Sistema Indústria”! Parabéns!

- Obrigado, Miguel! O time é muito competente e está muito integrado! Não teríamos chegado aonde chegamos sem a participaçáo de todos...

- Quanto à colaboraçáo com os parceiros, também vejo que temos muitas conquistas... Mas acho que podemos melhorar muita coisa... Fiz um relatório com a listagem de alguns pontos e queria saber o que você acha...

- Manda aí...

Miguel passou seu tablet para Armani, supervisor de produção do Sistema Indústria, que tirou seus óculos embaçados pela respiraçáo abafada pela máscara, para ler com atenção os seguintes itens:

1. Realização de inventário de ventiladores mecânicos do Estado pendentes - prometeram 2.000 ventiladores mecânicos e até agora entregaram 30 aparelhos;

2. Dimensionamento das demandas dos equipamentos de saúde públicos e estruturação de logística de distribuiçáo dos produtos - o governo regional, na verdade, não conhece com propriedade a sua própria estrutura, dimensionando suas demandas de forma muito precária;

3. Aprofundamento dos requisitos dos produtos e validação dos protótipos por parte dos órgãos de saúde - o conhecimento acerca do assunto está completamente fragmentado, dificultando o trabalho; os especialistas do sistema regional de saúde naturalmente são médicos, enfermeiros e fisioterapeutas, desconhecendo completamente os requisitos de engenharia para a fabricação dos equipamentos médico-hospitalares;

4. Direitos de propriedade intelectual - ninguém definiu nada ainda sobre a apropriação de eventuais ganhos com as soluções que estão sendo desenvolvidas;
5. Estrutura de governança - as ações de cooperação se consolidaram em função das entregas e da prestação de contas de um projeto de inovação, mas as instituições proponentes não possuem nenhum acordo acerca das estruturas de decisão;

6. Modelo de gestão do conhecimento e planejamento de longo prazo - a todo momento problemas surgiam, desafiando os times a encontrarem novas soluções, gerando um laboratório vivo sem qualquer tipo de registro ou perspectiva de criação de competências organizacionais de longo prazo.

Armani estava bastante envolvido com as operaçóes e naturalmente ainda não tinha pensado em nada daquilo. Parabenizou Miguel de forma desconcertada e sugeriu que tratasse do assunto com os diretores do Sistema Indústria para que pudessem traçar estratégias para o fortalecimento da cooperação interinstitucional.

- Sem dúvida, Armani! É justamente isso o que eu vou fazer, mas queria ouvir primeiro a sua opinião justamente por estar envolvido com os desafios do dia a dia... Precisava validar minhas percepçóes... Muito obrigado por sua ajuda!

\section{DILEMAS DE MIGUEL}

Todos os envolvidos tinham a nítida sensação de estarem trabalhando muito mais do que o habitual, tanto aqueles alocados na linha de frente quanto os times de suporte atuando no modelo de home office. No entanto, as conquistas obtidas eram muito gratificantes e claramente fortaleciam a motivação e o comprometimento dos funcionários e voluntários. Miguel, entretanto, buscava identificar as falhas no processo colaborativo e os desafios emergentes a serem enfrentados.

Miguel não parava de pensar... Como gerenciar efetivamente uma rede de instituiçóes para lidar com desafios que extrapolam as fronteiras organizacionais do Sistema Indústria? Como capturar as demandas do sistema regional de saúde rapidamente e distribuir as informaçôes de forma assertiva para as devidas partes interessadas? Dada a impossibilidade de utilização dos mecanismos tradicionais de comando e controle organizacional, o que o Sistema Indústria poderia fazer para alinhar diferentes atores em torno do mesmo propósito de combate à COVID-19? Miguel se debruçava sobre essas questóes e sobre como poderia dar respostas a cada uma delas. 


\section{RESUMO}

Com a ocorrência da pandemia da COVID-19 em 2020, tornou-se imperiosa a adoção de medidas emergenciais no sentido de evitar uma crise do sistema de saúde no nordeste do Brasil. Nesse contexto, Miguel Bastos, gerente do Sistema Indústria, entidade de classe do setor industrial nordestino, dedicou todos os seus esforços para coordenar uma rede emergente de instituições envolvidas em processos de pesquisa, desenvolvimento, inovaçáo, fabricação e manutenção de produtos demandados pelo sistema de saúde. Dessa forma, este caso de ensino tem como objetivo permitir que os alunos entendam o contexto de uma rede de cooperaçáo criada para suprir as necessidades do setor de saúde no combate à pandemia de COVID-19. Face às dificuldades inerentes a um processo de liderança envolvendo sete instituiçóes diferentes, como o protagonista deve organizar essa rede para atender às demandas previstas? O caso tem como públicos-alvo os alunos de Graduação em Administração, bem como de cursos de pós-graduação lato sensu, em disciplinas como Estratégia Empresarial, Redes de Cooperação, Parcerias Público-Privadas, dentre outras que abordem os temas propostos no presente caso. Ressalta-se que os dados foram coletados a partir de observação participante, dados secundários e entrevistas. Os personagens são reais, mas os nomes são fictícios.

Palavras-chave: inovação em rede; governança colaborativa; gestáo de crises e emergências; pandemia da COVID-19.

\section{Fontes e métodos de coleta}

O presente caso de ensino é baseado em fatos reais. Os dados foram coletados a partir de observação direta, observação participante, dados secundários e entrevistas com os personagens. Os personagens são reais, mas os nomes foram alterados para que suas identidades fossem preservadas.

\section{Objetivos educacionais e utilização recomendada}

Este caso tem por objetivo permitir que os alunos entendam o contexto de uma rede de cooperaçáo criada para suprir as necessidades do setor de saúde no combate à pandemia de COVID-19. A proposta é fazer com que os alunos analisem os dados e o contexto, coloquem-se no lugar do protagonista e discutam as melhores alternativas de solução para o dilema que está posto. Características como criatividade e pensamento crítico sáo fomentadas para a

\section{ABSTRACT}

With the occurrence of the COVID-19 pandemic in 2020, it became imperative to adopt emergency measures to prevent a crisis in the health system in northeastern Brazil. In this context, Miguel Bastos, manager of Sistema Indústria, a class entity in the northeastern industrial sector, dedicated all his efforts to coordinate an emerging network of institutions involved in research, development, innovation, manufacturing, and maintenance of products demanded by a health system. Thus, this teaching case aims to allow students to understand the context of a cooperation network created to meet the needs of the health sector in combating the pandemic of COVID-19. Given the difficulties inherent in a leadership process involving seven different institutions, how should the protagonist organize this network to meet the expected demands? The case has as target audience undergraduate Business Administration students, as well as lato sensu graduate courses, in subjects such as Business Strategy, Cooperation Networks, Public-Private Partnerships, among others that address the themes proposed in the present case. It is noteworthy that authors collected data from participant observation, secondary data, and interviews. The characters are real, but the names are fictitious.

Keywords: network innovation; collaborative governance; crisis and emergency management; COVID-19 pandemic.

tomada de decisão neste caso de ensino. Nessa linha, o caso tem ainda os seguintes objetivos educacionais:

1. Compreender os desafios da gestáo interinstitucional em um contexto de crises e emergências;

2. Entender as condiçôes iniciais para colaboração, bem como o papel da liderança no processo colaborativo;

3. Aprender sobre a construção e o progresso do processo de colaboraçáo em contexto de crise.

Do ponto de vista da utilização recomendada, o caso foi desenvolvido para propiciar a exploraçáo de conceitos relacionados às áreas de Estratégia, Redes de Cooperaçáo, Governança de Redes e Gestão Pública. Dessa forma, o caso pode ser aplicado em cursos de Graduação em Administração, bem como em cursos de pós-graduação lato sensu (especializaçóes e MBAs), em disciplinas como Estratégia Empresarial, Redes de Cooperação, Parcerias Público-Privadas, dentre outras que abordem os temas propostos no presente caso. 


\section{Plano de aula}

O caso pode ser aplicado em uma sessão tradicional com duração de duas horas/aula. Seguem recomendaçóes de aplicação antes da aula em que o caso será utilizado: (a) dividir a turma em grupos de três a cinco alunos; (b) disponibilizar o caso aos alunos previamente, com tempo suficiente para leitura e preparação das respostas; (c) disponibilizar as perguntas para discussão; (d) recomendar aos alunos que individualmente respondam às perguntas antes da aula.
No momento da aula, durante a aplicaçáo do caso, o professor deve orientar que as equipes se reúnam e discutam as respostas individuais, buscando uma solução (ou soluçôes) que represente o entendimento de seus membros. Em seguida, as equipes devem se reunir em plenária para apresentar e discutir suas análises e soluçôes com toda a sala. O professor deve conduzir todo esse processo e, ao final, fazer o fechamento da aula, apresentando e conectando a teoria utilizada para embasar o caso de ensino.

No intuito de apoiar o professor na condução do caso em sala de aula, sugere-se seguir o plano de aula apresentado na Tabela 1.

Tabela 1. Sugestão de plano de aula.

\begin{tabular}{|c|c|}
\hline Atividade & Duração (minutos) \\
\hline Apresentação geral do caso e detalhamento dos objetivos educacionais, conduzidos pelo professor. & 10 \\
\hline $\begin{array}{l}\text { Debate em grupos sobre o caso, considerando seus acontecimentos e contexto, abordando as questóes que estão descritas na seção } \\
\text { "Questôes para discussão". }\end{array}$ & 40 \\
\hline Apresentação em plenária e debate acerca das respostas, análises e soluções propostas pelos grupos. & 30 \\
\hline Conclusão geral do caso, conduzida pelo professor. & 20 \\
\hline Total & 100 \\
\hline
\end{tabular}

Nota. Fonte: Elaborado pelos autores.

\section{Questões para a discussão}

1. Gerenciamento interinstitucional: Como ocorreu a gestão interinstitucional no que diz respeito à mobilização, aos acordos organizacionais, à condução das interaçóes, às estratégias e às metas?

2. Condiçóes iniciais de colaboração: Quais eram as condições iniciais de colaboração, principalmente nos aspectos relacionados a assimetrias de poder, recursos e conhecimentos e construção de confiança?

3. Liderança facilitadora: Qual o papel da liderança no processo de construçáo da colaboraçáo, bem como para os resultados que foram atingidos?

4. Desenho institucional: Como o desenho institucional impactou o processo de colaboração? Qual o papel de cada instituição nesse processo, bem como das influências institucionais mútuas?

5. Processos colaborativos: De que forma a colaboração foi construída? Comente sobre aspectos relacionados à construção de confiança, compromisso, entendimento compartilhado, dentre outros.

\section{Análise do caso com suporte da literatura}

As questôes para discussão foram estabelecidas em torno dos objetivos educacionais e de aprendizagem e em função de categorias de análise pertencentes à literatura de governança colaborativa - um tipo de governança que reúne atores públicos e privados em fóruns de tomada de decisão orientados para o consenso, de modo que possam, de diferentes formas, utilizando processos particulares, estabelecer leis e regras para a provisão de ganhos coletivos (Ansell \& Gash, 2008).

Nesse contexto, entende-se que a qualidade das relaçóes sociais de uma localidade (no caso, o Nordeste) tem um efeito importante na vida social e no desempenho dos negócios e depende de alguns fatores essenciais, tais como uma infinidade de associações cívicas, um alto nível de interação entre os grupos sociais, coalizóes para além dos interesses individuais, um forte senso de objetivos comuns e a garantia dos direitos de propriedade (Healey, 1995; North \& Thomas, 1973).

Para que possa, portanto, ser efetiva, a governança colaborativa deve resultar de uma pluralidade de interaçóes entre entidades das esferas pública e privada (Klijn, 2014). Mas é pouco provável que as partes, por mais capazes que sejam, colaborem espontaneamente, sem que um gestor promova e assegure a integridade do próprio processo de construção do consenso. A partir de uma perspectiva de rede ou interinstitucional, a elaboração e a implementação de políticas são um processo complexo. Resultados interessantes para os atores envolvidos náo surgem imediatamente, mas precisam ser geridos e coordenados cuidadosamente. 
Destacam-se, então, como elementos cruciais da governança colaborativa os seguintes aspectos: o gerenciamento interinstitucional, as condições iniciais de colaboração, a liderança facilitadora, o desenho institucional e os processos colaborativos, que, em conjunto, voltam-se para o alcance de resultados. Com base nesses elementos, finalmente são propostas as seguintes questôes para discussão, bem como proposições respectivas de respostas:

1. Gerenciamento interinstitucional: Como ocorreu a gestão interinstitucional no que diz respeito à mobilização, aos acordos organizacionais, à condução das interações, estratégias e metas?
Em suma, o papel do gestor a partir de uma perspectiva de rede interinstitucional é equivalente ao de um mediador, de um gestor de processo. Isso porque a gestão de rede é, em essência, uma atividade interinstitucional. Está claro, entretanto, que se o gestor de rede deve atingir resultados importantes, uma variedade de estratégias diferentes é requerida (Klijn, 2014).

A governança colaborativa, portanto, caracteriza-se como um processo de gerenciamento interinstitucional, cujas atividades principais, que diferem significativamente das práticas de gestão intraorganizacional, constituem-se como estratégias direcionadas para a gestão da própria rede e de suas interaçóes, conforme destaca a Tabela 2.

Tabela 2. Estratégias de governança em rede.

\begin{tabular}{|c|c|c|}
\hline Estratégias & Gestão de interações & Gestão de rede \\
\hline Ativação de atores e recursos & $\begin{array}{l}\text { Ativação seletiva, mobilização de recursos, } \\
\text { estabilizaçáo, desativaçáo de atores e recursos, } \\
\text { iniciaçáo de novas séries de interaçãa, construção } \\
\text { de coalizóes }\end{array}$ & $\begin{array}{l}\text { Ativação de rede, mudança de composição da } \\
\text { rede, mudança de posição de atores, mudança } \\
\text { de recursos }\end{array}$ \\
\hline Estratégias para atingir metas & $\begin{array}{l}\text { Busca por congruência de metas, criação de } \\
\text { variações em soluçóes, influência (e explicação) } \\
\text { de percepção, gestão e coleta de informaçôes e } \\
\text { pesquisa }\end{array}$ & $\begin{array}{l}\text { Redefinição de percepçôes, mudança de papéis } \\
\text { decisórios em redes, mudança permanente de } \\
\text { fluxo de informações }\end{array}$ \\
\hline Acordos organizacionais & $\begin{array}{l}\text { Criaçáo de novos acordos organizacionais } \\
\text { (conselhos, organizaçóes de projetos, etc.) }\end{array}$ & $\begin{array}{l}\text { Criação de construçóes permanentes } \\
\text { organizacionais }\end{array}$ \\
\hline Condução de interaçóes & $\begin{array}{l}\text { Meditaçáo, intermediação, intervenção do } \\
\text { gestor do processo, remoçáo de obstáculos à } \\
\text { cooperaçấo, criaçáa de incentivos à cooperação }\end{array}$ & $\begin{array}{l}\text { Mudança de regras para regulaçáo de conflitos, } \\
\text { para fluxo de informação, mudança de regras de } \\
\text { pagamento ou códigos profissionais }\end{array}$ \\
\hline
\end{tabular}

Nota. Fonte: Adaptado de Klijn (2005).

Miguel enfrentou o dilema de gerenciamento interinstitucional definindo o papel de cada um dos atores integrantes da rede. Estabeleceu uma comunicação eficaz e célere por meio da criação de um grupo no WhatsApp, no qual todos tinham oportunidade de expor suas dificuldades e necessidades. Além disso, as visitas aos locais de trabalho e o contato mais próximo com os atores eram importantes para fortalecer a comunicação e as interaçóes entre as equipes. Em reunióes frequentes com Jairo, Miguel alinhava constantemente os objetivos e metas requeridos pelos demais atores e instituiçôes participantes da rede.

2. Condiçôes iniciais de colaboração: Quais eram as condiçôes iniciais de colaboração, principalmente nos aspectos relacionados a assimetrias de poder, recursos e conhecimentos e construção de confiança?

As condições iniciais da colaboração envolvem os desequilíbrios de recursos, conhecimento e poder, os antecedentes de cooperação ou conflito e os níveis de confiança entre as partes envolvidas, e iráo incentivar ou restringir a participação. Se houver significativos desequilíbrios, a governança eficaz requer uma estratégia de fortalecimento dos grupos sociais mais fracos.

A experiência de Miguel como gerente do Sistema Indústria, alinhada à sua posição no Conselho Superior da Fapne, foi fundamental para facilitar a coordenaçáo da rede. De certo modo, já existia um relacionamento entre as instituições e atores da rede, como participação em projetos de parceria, mas envolvendo no máximo duas instituiçóes. $\mathrm{O}$ ponto positivo era a inexistência de conflito entre os atores e as instituiçóes, mas, ao mesmo tempo, não havia uma curva de experiência com trabalhos colaborativos, muito menos para enfrentar um problema da envergadura de uma pandemia.

3. Liderança facilitadora: Qual o papel da liderança no processo de construçáo da colaboração, bem como para os resultados que foram atingidos? 
A liderança facilitadora coincide com o gestor interinstitucional anteriormente apresentado e tem o papel de educar e incluir grupos mais fracos, bem como dar voz significativa aos participantes, encorajando-os a ouvir uns aos outros. $\mathrm{Na}$ ausência dos demais elementos de governança eficaz, a liderança facilitadora se torna mais crucial. Por outro lado, a colaboração pode ser seriamente afetada na falta de um líder capaz de mediar os processos de construção coletiva.

A definição do líder foi crucial para o sucesso do projeto. Era importante ter um gestor com conhecimento dos processos de cada instituição e também com um relacionamento interpessoal adequado, com boa liderança e que desenvolvesse bem a empatia com as equipes. Nesse sentido, a escolha de Miguel foi um fator que contribuiu para a construção de uma equipe colaborativa e disposta a alcançar as metas traçadas.

4. Desenho institucional: Como o desenho institucional impactou o processo de colaboração? Qual o papel de cada instituição nesse processo, bem como das influências institucionais mútuas?

O desenho institucional, por seu turno, refere-se à formalização das estruturas da governança, à definição clara dos papéis e a protocolos e regras cruciais para a transparência e para a legitimidade processual da colaboração. Caso existam espaços alternativos e unilaterais de decisão, só haverá colaboração se as partes forem altamente interdependentes.

A elaboração do projeto por Miguel, em colaboração com os diversos participantes da rede, contribuiu para a formalização de uma estrutura de governança, visto que foram definidos os papéis e as responsabilidades de cada instituição e cada uma estava ciente de suas influências mútuas.

5. Processos colaborativos: De que forma a colaboração foi construída? Comente sobre aspectos relacionados à construçáo de confiança, compromisso, entendimento compartilhado, dentre outros.

Os processos colaborativos, por último, envolvem o diálogo face a face, a construção de confiança e de compromisso entre as partes e o entendimento compartilhado do que se pode alcançar em conjunto. Não obstante, as partes não seguirão despendendo seu tempo com a colaboração se ao menos pequenas vitórias não forem atingidas.
O projeto empreendido pelos atores requereu um esforço maior do que o habitual. Todos foram envolvidos em propósitos que traziam um elemento extremamente motivador: levar um alívio às pessoas acometidas com a doença ou mesmo salvar vidas. A colaboração foi construída principalmente em torno desse propósito $\mathrm{e}$, alinhada às características pessoais da liderança e de cada ator participante, resultou em conquistas antes não imaginadas por cada instituição isoladamente.

Uma vez reunidos esses elementos, torna-se possível evitar altos custos de formulação de políticas, ampliar a participação democrática, envolver adversários em discussões produtivas, estabelecer relações frutíferas entre partes interessadas e desenvolver formas sofisticadas de aprendizagem e resolução de problemas.

Pressupóe-se, portanto, que a governança colaborativa é um meio potencialmente eficaz para a criação de um ambiente propício para o surgimento de empresas líderes e de um Estado visionário, que podem vir a deliberar sobre políticas de interesse coletivo.

Os resultados colaborativamente obtidos pelas equipes sob a liderança de Miguel demonstram o quanto é importante a adoção de um modelo de governança colaborativa e o desenvolvimento de processos colaborativos para o alcance de metas pretendidas.

\section{Desfecho}

Após três meses de isolamento social, os resultados obtidos com o projeto de inovação subvencionado pela Fapne e, principalmente, com o trabalho voluntário de dezenas de instituiçóes e milhares de pessoas foram inestimáveis no tocante à geração de alívio relacionado à crise sanitária. Mais de 100 ventiladores mecânicos do governo regional foram recuperados e puderam ser usados no atendimento de pelo menos 300 pacientes com COVID-19. Dezenas de milhares de equipamentos de proteção individual foram produzidas pelo Sistema Indústria e seus parceiros e doados para hospitais públicos e privados de todo o sistema regional de saúde. Além disso, o Sistema Indústria, em parceria com o Instituto Regional de Saúde e com a UFN, realmente conseguiu desenvolver um ventilador mecânico pulmonar de baixo custo, escalável e não invasivo, destacando-se como entidade provedora de tecnologia e inovação. 


\section{REFERÊNCIAS}

Ansell,C., \& Gash,A. (2008). Collaborativegovernance in theory and practice. Journal of public administration research and theory, 18(4), 543-571. https://doi.org/10.1093/jopart/mum032

Healey, P. (1995). The institutional challenge for sustainable urban regeneration. Cities, 12(4), 221-230. https://doi.org/10.1016/0264-2751(95)00043-L

Klijn, E. H. (2005). Networks and inter-organizational management: Challenging steering, evaluation and the role of public actors in public management. In E. Ferlie, L. Lynn, \& C. Pollitt (Orgs.). The Oxford Handbook of Public Management (pp. 275-281). Oxford: Oxford University Press.

\section{Autoria}

\section{Raphael Jesus Campos de Andrade*}

Universidade Federal do Ceará

Av. da Universidade, n 2486, Benfica, CEP 60020-180, Fortaleza, CE, Brasil

E-mail: raphaeldj.campos@gmail.com

(1) https://orcid.org/0000-0002-6062-2931

\section{José Milton de Sousa-Filho}

Universidade de Fortaleza, Programa de Pós-graduação em Administração

Av. Washington Soares, no 1321, Edson Queiroz, 60.811-905, Fortaleza, CE, Brasil

E-mail: miltonsousa@unifor.br

(D) https://orcid.org/0000-0002-3078-3179

\section{Fátima Evaneide Barbosa de Almeida}

Fundaçāo Cearense de Apoio ao Desenvolvimento Científico e Tecnológico

Av. Oliveira Paiva, no 941, Cidade Dos Funcionários, 60.822-

130, Fortaleza, CE, Brasil

E-mail: fatimaevaneide.almeida@gmail.com

(1) https://orcid.org/0000-0003-3751-7890

\section{Samuel Façanha Câmara*}

Universidade Estadual do Ceará, Programa de Pós-graduaçáo em Administração

Av. Dr. Silas Munguba, no 1700, Itaperi, 60740-000, Fortaleza, CE, Brasil

E-mail: samuel.camara@uece.br

(D) https://orcid.org/0000-0002-8333-6997

* Autor Correspondente

\section{Financiamento}

Os autores relataram que não houve suporte financeiro para a pesquisa deste artigo.
Klijn, E. H. (2014). Redes de política e implementação: Gerenciando interaçóes complexas (pp. 108-133). In S. Cropper, M. Ebers, C. Huxham, \& Ring, P. S. Handbook de relaçôes interorganizacionais da Oxford. Porto Alegre: Bookman.

North, D. C., \& Thomas, R. P. (1973). The rise of the western world: A new economic history. Cambridge: Cambridge University Press.

\section{Contribuições dos Autores}

$1^{\circ}$ autor: conceituação (liderança); metodologia (liderança); supervisão (liderança); escrita - rascunho original (liderança); escrita - revisão e edição (igual).

$2^{\mathbf{o}}$ autor: conceituação (igual); metodologia (igual); validaçãao (liderança); escrita - rascunho original (igual); escrita - revisão e edição (liderança).

$3^{\text {a }}$ autora: conceituação (igual); metodologia (igual); escrita - rascunho original (igual); escrita - revisão e edição (igual).

$4^{\mathbf{0}}$ autor: conceituação (igual); metodologia (igual); escrita rascunho original (igual); escrita - revisão e edição (igual).

\section{Conflito de Interesses}

Os autores informaram que não há conflito de interesses.

\section{Direitos Autorais}

A RAC detém os direitos autorais deste conteúdo.

\section{Verificação de Plágio}

A RAC mantém a prática de submeter todos os documentos aprovados para publicação à verificação de plágio, mediante o emprego de ferramentas específicas, e.g.: iThenticate.

\section{Método de Revisão por Pares}

Este conteúdo foi avaliado utilizando o processo de revisão por pares duplo-cego (double-blind peer-review). A divulgação das informaçôes dos pareceristas constantes na primeira página é feita somente após a conclusão do processo avaliativo, e com o consentimento voluntário dos respectivos pareceristas.

\section{Disponibilidade dos Dados}

A RAC incentiva o compartilhamento de dados mas, por observância a ditames éticos, não demanda a divulgação de qualquer meio de identificaçáo de sujeitos de pesquisa, preservando a privacidade dos sujeitos de pesquisa. A prática de open data é viabilizar a reproducibilidade de resultados, e assegurar a irrestrita transparência dos resultados da pesquisa publicada, sem que seja demandada a identidade de sujeitos de pesquisa. 